Abstracta Iranica Abstracta Iranica

Revue bibliographique pour le domaine irano-aryen

Volume 42-43 | 2021

Comptes rendus des publications de 2019-2020

\title{
Sven Günther. "Konstruierte Konituität. Die Münz- und Briefmarkenpropaganda zur 2500-Jahr-Feier der iranischen Monarchie 1971"
}

Reinhardt Pirngruber

\section{(2) OpenEdition Journals}

Electronic version

URL: https://journals.openedition.org/abstractairanica/53592

DOI: 10.4000/abstractairanica.53592

ISSN: 1961-960X

Publisher.

CNRS (UMR 7528 Mondes iraniens et indiens), Éditions de l'IFRI

\section{Electronic reference}

Reinhardt Pirngruber, "Sven Günther. "Konstruierte Konituität. Die Münz- und Briefmarkenpropaganda zur 2500-Jahr-Feier der iranischen Monarchie 1971'"', Abstracta Iranica [Online], Volume 42-43| 2021, document 2, Online since 30 December 2021, connection on 12 December 2022. URL: http:// journals.openedition.org/abstractairanica/53592 ; DOI: https://doi.org/10.4000/abstractairanica. 53592

This text was automatically generated on 12 December 2022.

All rights reserved 
Sven Günther. "Konstruierte Konituität. Die Münz- und Briefmarkenpropaganda zur 2500Jahr-Feier der iranischen Monarchie 1971"

\author{
Reinhardt Pirngruber
}

\title{
REFERENCES
}

Sven Günther. “Konstruierte Konituität. Die Münz- und Briefmarkenpropaganda zur 2500-Jahr-Feier der iranischen Monarchie 1971" in R. Rollinger, K. Ruffing, L. Thomas (eds.). Das Weltreich der Perser. Rezeption - Aneignung - Verargumentierung. Wiesbaden: Harrassowitz Verlag, 2019, p. 189-214.

S. Günther discusses the use of Achamenid motives - particularly prominent were the Cyrus cylinder and the tomb of Cyrus - on coins and stamps during the final years of the Pahlavi dynasty. Mohammed Reza Pahlavi aimed at presenting his dynasty as protectors of Iran's cultural heritage and as legitimate successors to the Achaemenids; a claim that was accepted rather uncritically by the world public. 


\section{AUTHORS}

\section{REINHARDT PIRNGRUBER}

Institut für Orientalistik, Wien 